\title{
COMPARISON OF EXTRA-SHORT-DURATION PIGEONPEA WTTH SHORT-SEASON LEGUMES UNDER RAINERD CONDITIONS ON ALFISOLS
}

\author{
By N. H. NAM, Y. S. CHAUHAN and C. JOHANSEN \\ Intemational Crops Research Institule for the Semi-Arid Tropics (ICRISAT), \\ Palancheru, Andhre Pradesh 502 324, India
}

(Accepled I Sepiember 1992)

\section{SUMMARY}

\begin{abstract}
Extra-ahon-duration pigeonpea (Cojenus cajum) genotypes generally yielded more than ahomseason legumea when sown at the normal time on rainfed medium-drep Alfialu. However, their growth and yield were more redured by delayed sowing and varied more widely between ceasona than those of the shart-ecason legumes, esprcially cowpen and black gram. All the crope gave kower yields on shallow Alfsols than on medium-deep Alfisola and none was conaituteatly superor. Partitioning of dry mutter into grain yield was lew affected by time of nowing, woll and cascon in extra-short-duration pigeonpea genotypes than in short-season legumes. Lew censitivity of biomass accumulation to various abiotic constraints is therefore a major objective in improving the adapeation of extra-short-duration pigeonpea genotypes.
\end{abstract}

Cajeans cajeas de duración extra-corle

\section{RESUMEN}

En líneas generales, los genotipos de Cajanus cajen de duración extra-corta presentaron mayor rendimiento que las legumbres de estación corta al sembrarac en tiempo normal en Alfisols de profundidad media regados por precipitaciones No obstante, su crecimiento y rendimiento sufricron una mayor reducción con el retraso en la sembra, y presenturon una mayor variación entre estaciones que los de las legumbres de estación corta, en eapecial, que el caupi y el garbanzo gram negro. Todos ba cultivos produjeron un menor rendimiento en los Alfieola de poca profundidad que en ko Alfisols de profundidad media, y ninguno resultó uniformemente superior. La distribución de materia seca en el rendimiento de grano se vio mís afectada por el tiempo de siembra, el suelo y la estación en los genotipos de Cajanus cajen de duracion extrt:corta que en las legumbres de catación corta. Por lo tanto, una menor senaibilidad de acumulación de biomana respecto de las diversas restricciones abibticas conutituye un importante objetivo en la mejora de la adaptación del Cajanus cajos de duración extra-corta.

\section{INTRODUCT̃ON}

Pigeonpea (Cajenus cajan [L.] Millsp.) is an important tropical grain legume crop grown under rainfed conditions in the semi-arid tropics. Traditional pigeonpea genotypes are usually grown as intercrops, with the main crop being harvested at the end of the rainy season and the pigeonpea continuing to grow well into the dry seapon, utilizing residual soil moisture. The duration (time from sowing to maturity) of traditional pigeonpea genotypes normally exceeds 25 meels and when the rainy period is less than 15 weeks they invariably face drought stresis towards the end of their growing season (Singh and Subbe Reddy, 1989). This 
stress may be avoided by using the recently developed short-duration (SD) pigeonpea genotypes, which mature in 17-20 weeks (Chauhan, 1990). However, such genotypes are not suitable for intercropping as they would compete with the companion crop for the same resources over a similar growing period. Yield of both SD and traditional pigeonpea genotypes may be markedly reduced by delayed sowing (Chauhan, 1990). Thus they are not suitable for contingency cropping (alternatively termed catch cropping), which is defined as the use of substitute crops sown after the recommended sowing period of regular crops or after a regular crop has failed (Martin et al., 1976). Other short-season (SS) grain legumes, such as cowpea (Vigna unguiculata [L.] Walp.), green gram (Vigna radiata [L.] Wilezek), black gram (Vigna mungo [L.] Hepper) and horse gram (Macrolyloma uniforum [Lam.] Verdc.), are suitable for this purpose because they mature rapidly (typically in 9-13 weeks) (Subramaniam, 1983). To extend the cultivation of pigeonpea to such cropping situations, genotypes that mature more quickly than SD genotypes are required (Troedson et al., 1990). Recently, a number of extra-short-duration (ESD) genotypes that mature in 90-100 days have been developed (Laxman Singh et al., 1990) but information on their adaptation to rainfed conditions is lacking. Such genotypes need to be competitive with the SS legumes that are already grown in water-limited, short-growing period environments, and to be suitable for use as a contingency crop.

The objective of the present study was to compare the growth patterns and yield of ESD pigeonpea genotypes and commonly grown SS legumes at different sowing dates and in different environments. Experiments were conducted at two sites, which differed greatly in rainfall pattern and soil moisture holding characteristics.

\section{MATERIALS AND METHODS}

The experiments were carried out on medium-deep (less than $0.9 \mathrm{~m}$ ) Alfisols (Udic Rhodustalf) at the ICRISAT Center, Patancheru $\left(18^{\circ} \mathrm{N}, 78^{\circ} \mathrm{E}\right)$ and on shallow (less than $0.5 \mathrm{~m}$ ) Alfisols at Anantapur $\left(15^{\circ} \mathrm{N}, 73^{\circ} \mathrm{E}\right)$ in peninsular India, during the rainy seasons of 1988 and 1989. The plant-available water holding capacity of Alfisols is less than $100 \mathrm{~mm}$ at the ICRISAT Center (Venkataratnam and Sheldrake, 1985) and less than $50 \mathrm{~mm}$ at Anantapur (Singh and Subba Reddy, 1988). Monthly rainfall and temperatures during the cropping seasons were recorded and soil moisture storage calculated using the water balance model 'WATBAL' of Keig and McAlpine (1974). A basal dose of $100 \mathrm{~kg} \mathrm{ha}^{-1}$ diammonium phosphate ( $18 \% \mathrm{~N}$ and $20 \% \mathrm{P}$ ) was incorporated before sowing.

At both locations, experiments were conducted using a split-plot design with four replications. The sowing dates were assigned to main plots and pigeonpea genotypes and SS legume species to sub-plots. The sowing dates at the ICRISAT Center were 20 June (normal) and 5 August (delayed) in 1988 and 30 June and 3 August in 1989. These represent the normal sowing time and up to four to six weeks delay, which could in practice occur as a result of such circumstances as the 
delayed onset of the rains, and unavailability of inputs. At Anantapur, the two sowing dates were 27 July and 15 September in 1988 and 11 July and 18 August in 1989. Five ESD pigeonpea genotypes (ICPL 83015, ICPL 84023, ICPL 85014, ICPL 85015 and ICPL 85037), an SD pigeonpea genotype (ICPL 87) and three SS legumes (green gram PS 16, horse gram 'local' and cowpea C. 152) were used in 1988. In the following year, only four ESD pigeonpea genotypes (ICPL 83015, ICPL 84023, ICPL 85014 and ICPL 85015) were compared with the same three SS legumes and one additional genotype of black gram (T 9). In this paper, two representative ESD genotypes, ICPL 83015 and ICPL 84023, are compared with ICPL 87 and the SS legumes, as the performance of pigeonpea genotypes ICPL 83015, ICPL 85014 and ICPL 85015 was similar in both years.

At the ICRISAT Center, sowing was done by hand in furrows opened on both sides of ridges $60 \mathrm{~cm}$ wide. Inter-row spacing was $30 \mathrm{~cm}$ and intra-row spacing 10 $\mathrm{cm}$. The gross sub-plot size was $3 \times 4 \mathrm{~m}$. At Anantapur, sowing was into flat beds with the same inter- and intra-row spacings as used at the ICRISAT Center. Two seeds per hill were sown and the seedlings thinned to one per hill 25-30 days after sowing (DAS). At the ICRISAT Center, pre-emergence herbicides, fluchloralin at $0.75 \mathrm{~kg}$ active ingredient (a.i.) ha ${ }^{-1}$ and prometryn at $1.25 \mathrm{~kg}$ a.i. ha ${ }^{-1}$ mixed together in a tank, were sprayed on the soil soon after sowing. In addition, the plots were hand weeded twice at monthly intervals. At Anantapur, the weeds were controlled by hand weeding alone. The crops at both the locations were sprayed with $0.07 \%$ endosulfan ( 35 EC) to minimize losses from attack by pod borer (Helicoverpa armigera) and spotted borer (Maruca testulalis).

Time to flowering was recorded as the time when $50 \%$ of the plants had at least one open flower and time to maturity when about $85 \%$ of the pods were mature. For growth analysis in the 1988 season at the ICRISAT Center, three plants were sampled from each plot one month after sowing and then at two-week intervals. Leaf area was measured on an automatic leaf area meter (Delta $T$ Devices) and dry matter (DM) of separated plant parts was recorded after drying to constant weight. At harvest, total dry matter (TDM) was estimated from one row in each plot $\left(1.14 \mathrm{~m}^{2}\right)$. Grain was harvested from a net plot size of about $4.8 \mathrm{~m}^{2}$. Yield components were determined from sub-samples, each of five plants.

\section{RESULTS}

\section{Weather and soil moisture}

The total rainfall received during the two rainy seasons (June-September) was similar at both sites and was greater than the long-term average (Table 1). Rainfall distribution was more even in 1988 than in 1989. At the ICRISAT Center, soil moisture increased rapidly from mid-June, coinciding with the time of the normal sowings, and the soil profile was filled to capacity within four or five weeks (Fig. 1). There was little run-off during this period. However, from midJuly, the time of the delayed sowings, there was considerable run-off. Although soil moisture build-up and depletion showed the same general trend in both the 
1988 and 1989 seasons, the intensity of run-off and its timing differed between the seasons. At Anantapur, soil moisture accumulation and depletion, as well as runoff, differed between the two seasons. In both seasons, soil moisture fluctuated more widely during the rainy season than at the ICRISAT Center. Symptoms of intermittent stress were observed during crop growth.

\section{Crop development}

Delayed sowing did not consistently influence time to flowering of the pigeonpea genotypes and green gram at the ICRISAT Center, but accelerated maturity in all the crops in both seasons (Table 2). Genotype $\times$ sowing date interactions for time to flowering and maturity were significant in both seasons. Horse gram sown at the normal time did not flower until after the other crops had been harvested in 1988, and was the last crop to flower in 1989, whereas the other SS legumes flowered and matured earlier than the ESD pigeonpea genotypes.

There were significant differences in leaf area index (LAI) among the different crop species and between the different sowing dates at most recording dates at the ICRISAT Center in 1988 (Fig. 2). Generally, all crops attained a maximum LAI at 60-75 DAS, except horse gram, which attained a maximum 90 days after delayed sowing.

Accumulation of dry matter in the 1988 growing season at the ICRISAT Center was more rapid and occurred over a longer period after normal sowing than after delayed sowing (Fig. 2). Cowpea and horse gram suffered from lodging in the normal sowing. In both sowings, dry matter accumulation was most rapid in cowpea. In the normal sowing, differences in dry matter accumulation between

Table 1. Rainfall (mm) and temperature (C) during the 1988 and 1964 seasons at the ICRISAT Cenier and at Anonlapur, compared unth long-lem mean

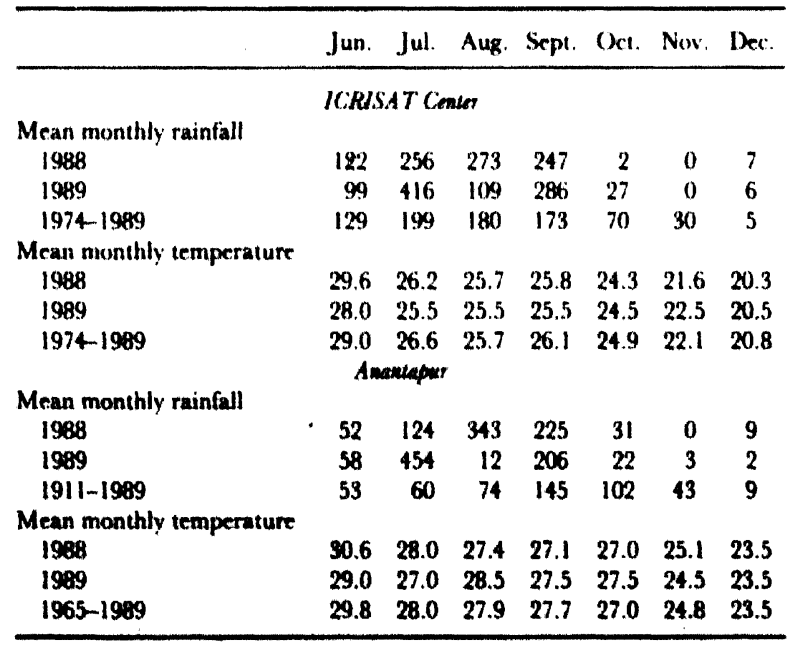




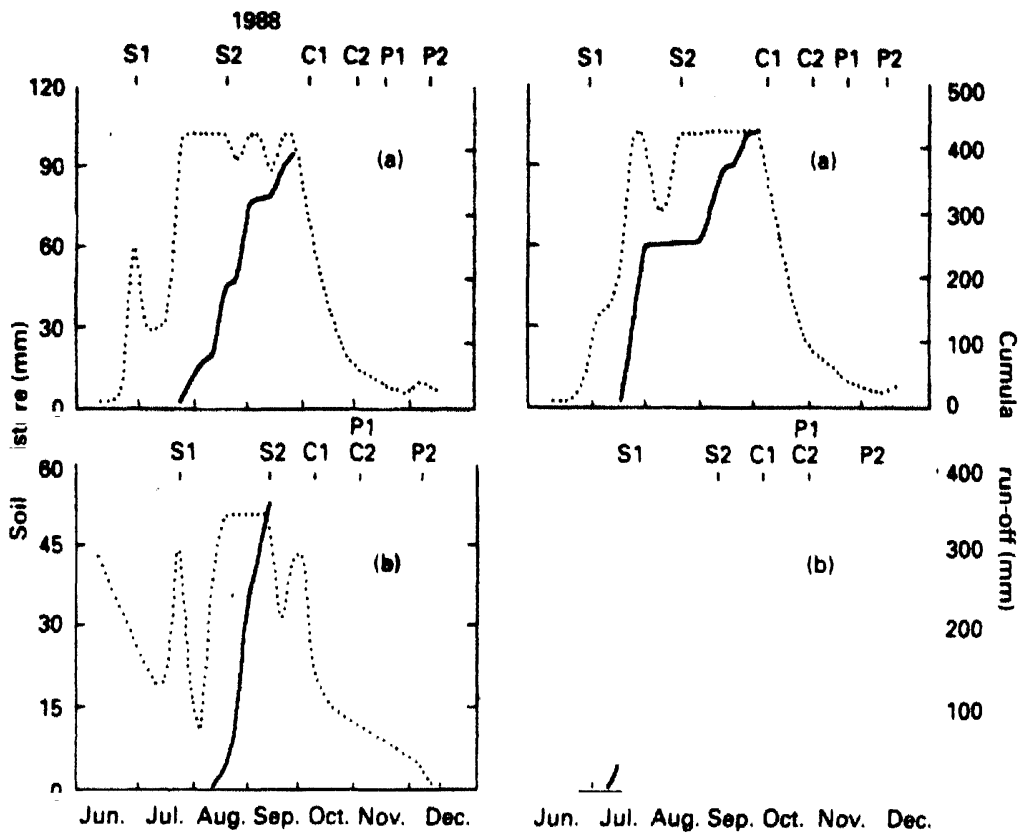

Fig. 1. Simulated soil moisture storage (broken line) and cumulative rutı-ell (solid line) on (a) mediumdeep Alfisols at the IC'RISAT Center and (b) shallow Altisols al Anantapur during the cropping periods of 1988 and 1989 . S1 indicates the normal and $\$ 2$ the delayed sowing time, (i) the normal and (:2 the delayed harvest time for cowpea, and $\mathrm{Pl}$ the normal and $\mathrm{P}_{2}$ the delayed harvest time for pigeonpea.

Table 2. Time (d) wo S0\% flouering and malurity of ESSD and SD pigeonpea genstypes and other shotl-season legumes after nomal and delayed souring in 1948 and 1954 on Alfusols at the ICRISAT Cienter

\begin{tabular}{|c|c|c|c|c|c|c|c|c|}
\hline & \multicolumn{4}{|c|}{1988} & \multicolumn{4}{|c|}{1989} \\
\hline & \multicolumn{2}{|c|}{$50 \%$ flowering } & \multicolumn{2}{|c|}{ Maturity } & \multicolumn{2}{|c|}{$50 \% \%$ flowering } & \multicolumn{2}{|c|}{ Maturity } \\
\hline & Normal & Delayed & Normal & Delayed & Normal & Delayed & Normal & Delayed \\
\hline \multicolumn{9}{|l|}{ Pigeunpea } \\
\hline ICPI. 83015 & 55 & 58 & 115 & 97 & 59 & 5.5 & 111 & 101 \\
\hline IC:PL 84023 & 49 & 54 & 102 & 94 & 54 & 49 & 104 & 101 \\
\hline ICPL. 87 & 60 & 64 & 135 & 115 & - & - & - & - \\
\hline \multicolumn{9}{|l|}{ SS legumes } \\
\hline Green gram & 35 & 41 & 67 & 64 & 38 & 37 & 81 & 71 \\
\hline Black gram & - & - & - & - & 36 & 35 & 91 & 73 \\
\hline Horse gram & - & 66 & - & 122 & 91 & 59 & 126 & 128 \\
\hline Cowpea & 54 & 45 & 88 & 70 & 44 & 41 & 85 & 72 \\
\hline $\mathbf{S E}+$ & \multicolumn{2}{|c|}{1.2} & \multicolumn{2}{|c|}{0.4} & \multicolumn{2}{|c|}{0.5} & \multicolumn{2}{|c|}{0.6} \\
\hline
\end{tabular}

†Standard error for comparing means within and between sowing dates. 
the two ESD pigeonpea genotypes were apparent from 60 DAS. There was very little increase in dry matter beyond 60 DAS in the delayed sowing in any of the pigeonpea genotypes or in horse gram, but sowing date $\times$ genotype interactions for total dry matter at harvest were highly significant at both locations in 1988 (Table 3).

Grain yield, yield components and rainfall use efficiency

Grain yiclds of pigeonpea were much higher in 1988 than in 1989 and genotype ICiPL 83015 consistently yielded more than all the other crops after normal sowing at the ICRISAT Center (Table 4). However, within each season, the effects of sowing date, genotype and genotype $X$ sowing date interactions were highly significant. At Anantapur grain yields were very poor and differences in grain yield between the two seasons were relatively small (Table 4). The eflects of sowing data, genotype and interactions between genotype and sowing data were

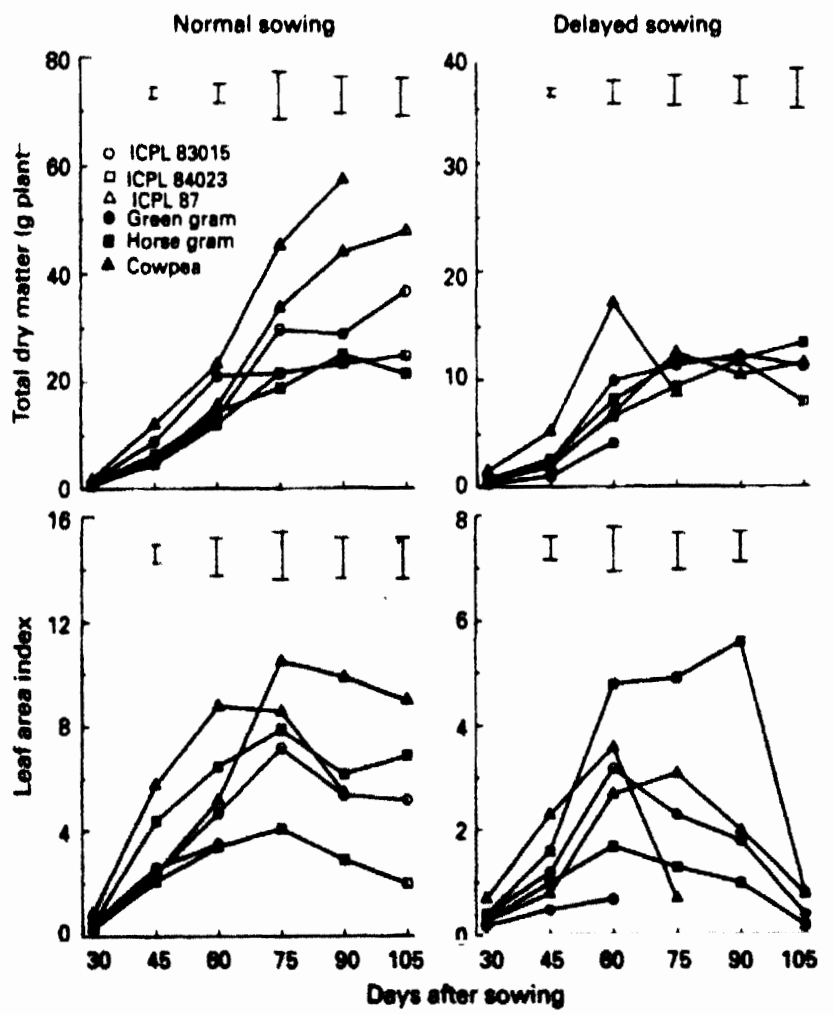

Fig. 2. Leaf area index and dry matter accumulation in the ESD pigeonpea genotypes and short-season legumes in normal and delayed sowings at the ICRISAT Center in 1988 (vertical bars denote standard errors at $P<0.05$ ). 


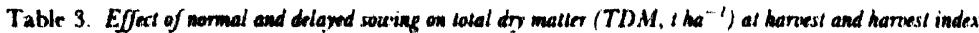
(HI) of pigrempere and other short-season legume crops groux on medium-deep Alfisols at the ICRIS.AT Center and on shalloer Alfsols at Amentapur in the rainy season. 1988

\begin{tabular}{|c|c|c|c|c|c|c|c|c|}
\hline \multirow[t]{3}{*}{ r } & \multicolumn{4}{|c|}{ ICRISAT Center } & \multicolumn{4}{|c|}{ Anantapur } \\
\hline & \multicolumn{2}{|c|}{ TDM } & \multicolumn{2}{|c|}{ HI } & \multicolumn{2}{|c|}{ TDM } & \multicolumn{2}{|c|}{ HI } \\
\hline & Normal & Delayed & Normal & Delayed & Normal & Delayed & Normal & Delayed \\
\hline \multicolumn{9}{|l|}{ Pigeonpea } \\
\hline IC.PI. 83015 & 8.52 & 3.21 & 0.34 & 0.32 & 1.76 & 1.17 & 0.29 & 0.25 \\
\hline IC.PL 84023 & 5.72 & 2.92 & 0.34 & 0.34 & 2.0 .3 & 1.06 & 0.34 & 0.27 \\
\hline IC:PI. 87 & 8.30 & 3.13 & 0.30 & 0.26 & 2.00 & 1.01 & 0.17 & 0.37 \\
\hline \multicolumn{9}{|l|}{ SS legumes } \\
\hline Green gram & 3.02 & 1.02 & 0.22 & 0.39 & $2.06 \mathrm{i}$ & 0.36 & 0.13 & 0.41 \\
\hline Horse gram & 4.36 & 3.47 & -+ & 0.29 & 2.68 & 1.06 & 0.22 & 0.40 \\
\hline Cowpra & 5.40 & 3.19 & 0.24 & 0.46 & 5.04 & 0.83 & 0.18 & 0.44 \\
\hline $\mathrm{SE}^{+}$ & \multicolumn{2}{|c|}{$\begin{array}{c}0.439 \\
(0.434)^{+}\end{array}$} & \multicolumn{2}{|c|}{$\begin{array}{c}0.022 \\
(0.028)\end{array}$} & \multicolumn{2}{|c|}{$\begin{array}{c}0.240 \\
(0.220)\end{array}$} & \multicolumn{2}{|c|}{$\begin{array}{c}0.023 \\
(0.029)\end{array}$} \\
\hline
\end{tabular}

tYirld of horse gram not obtained, and data from the second sowing not included in the analysis: ¡values in parentheses are the standard errors used for comparing means within a sowing date.

Table 4. Effecl of normal and delayed sou'ing on grain yield ( 1 ha ") of pigeonpen and other short-season legume ciops groun on medium-deep Alfisols at the ICRIS.AT Cemter and on shallowe Alfsols at Anantapur in the rainy seasons of 1988 and 1.989 .9

\begin{tabular}{|c|c|c|c|c|c|c|c|c|}
\hline & \multicolumn{4}{|c|}{1988} & \multicolumn{4}{|c|}{1989} \\
\hline & \multicolumn{2}{|c|}{ ICRISAT Center } & \multicolumn{2}{|c|}{ Anantapur } & \multicolumn{2}{|c|}{ ICRISAT Center } & \multicolumn{2}{|c|}{ Anantapur } \\
\hline & Normal & Ixelayed & Normal & Delayed & Normal & Delayed & Normal & Delayed \\
\hline \multicolumn{9}{|l|}{ Pigeonpea } \\
\hline ICPI. 83015 & 2.86 & 1.02 & 0.51 & 0.28 & 1.74 & 0.32 & 0.58 & 0.20 \\
\hline ICPI. 84023 & 1.96 & 1.01 & 0.69 & 0.29 & 1.36 & 0.51 & 0.51 & 0.07 \\
\hline ICPL 87 & 2.47 & 0.78 & 0.31 & 0.37 & - & - & - & - \\
\hline \multicolumn{9}{|l|}{ SS legumes } \\
\hline Green gram & 0.68 & 0.40 & 0.26 & 0.15 & 1.00 & 0.15 & 0.03 & 0.10 \\
\hline Black gram & - & - & - & - & 1.51 & 0.70 & 0.09 & 0.16 \\
\hline Horse gram & $-t$ & 0.99 & 0.58 & 0.42 & 0.18 & 0.59 & 1.06 & 0.30 \\
\hline Cowpea & 1.26 & 1.41 & 0.88 & 0.37 & 1.32 & 1.04 & 0.09 & 0.32 \\
\hline $\mathbf{S E}$ & \multicolumn{2}{|c|}{$\begin{array}{c}0.128 \\
(0.126)\end{array}$} & \multicolumn{2}{|c|}{$\begin{array}{c}0.051 \\
(0.038)\end{array}$} & \multicolumn{2}{|c|}{$\begin{array}{c}0.075 \\
(0.077)\end{array}$} & \multicolumn{2}{|c|}{$\begin{array}{c}0.076 \\
(0.075)\end{array}$} \\
\hline$C V(\%)$ & \multicolumn{2}{|c|}{16.5} & \multicolumn{2}{|c|}{18.0} & \multicolumn{2}{|c|}{17.3} & \multicolumn{2}{|c|}{43.0} \\
\hline
\end{tabular}

$\uparrow$ Yield of hone gram not obtained, and data from the second sowing not included in the analysis in the 1968 season; †values in parentheses are the standard errors used for comparing means within a sowing date. 
highly significant in both seasons. Differences among the crops and genotypes were generally not significant in the delayed sowings and no crop genotype consistently outyielded the others whatever the sowing date or season.

The harvest index of the ESD genotypes was relatively less variable across sowing dates and locations than that of the SS legumes, which increased significantly after delayed sowings at both locations (Table 3 ). Number of pods $\mathrm{m}^{-2}$ and 100-seed mass of ESD genotypes declined significantly after delayed sowing at the ICRISAT Center, but the SS legumes were less affected and showed a marginal increase in these characteristics with delayed sowing (data not shown). At Anantapur, the number of pods $\mathrm{m}^{-2}$ declined after delayed sowing in all the crops but the differences were not significant. Genotype $\times$ sowing date interaction was significant for 100-seed mass. However, number of seeds pod ${ }^{-1}$ was not influenced by sowing date or its interaction with genotype.

Rainfall use efficiency for grain yield (RUE), expressed as $\mathrm{kg} \mathrm{ha}^{-1} \mathrm{~mm}^{-1}$ water (rainfall minus simulated run-off), for ESD genotypes in normal sowings ranged from 4.0 to 5.8 in 1988 and from 3.1 to 4.1 in 1989. In the delayed sowings, RUE values for ESD genotypes ranged from 2.9 to 4.0 in 1988 and from 1.3 to 2.0 in 1989. The RUE values of cowpea, which were generally more than those of other SS legumes, were 3.0 in 1988 and 3.1 in 1989 after normal sowing, and 5.9 in 1988 and 4.2 in 1989 after delayed sowing.

\section{DISCUSSION}

On the medium-deep Alfisols at the ICRISAT Center, the ESD pigeonpea genotype ICPL 83015 gave the highest grain yields and had the highest RUE of all the crops tested after normal sowings in both years. Its yields were not only significantly greater than the earlier maturing SS legumes but were also higher than those crops which matured later, such as ICPL 87 and horse gram, and compared favourably with reported yields of medium-duration pigeonpea genotypes traditionally adapted to this environment (Venkataratnam and Sheldrake, 1985). But in both seasons there was above-average rainfall, although, as simulation data suggest, much of it was lost as run-off and therefore may not have been accessible for plant growth. The better grain yield of the ESD pigeonpea genotypes in 1988 might have been due to a better distribution of rainfall that year than in 1989. Horse gram was the lowest yielding crop after normal sowing in both seasons, probably because it is photoperiod-sensitive and susceptible to lodging.

There was a significant reduction in TDM production in all the crops after delayed sowing, resulting from less rapid accumulation of dry matter over a shorter season. It could be that the reduced rate of dry matter accumulation in all the late sown crops occurred because their early growth coincided with saturated soil conditions. Such conditions have been reported to reduce the availability of oxygen considerably and therefore the growth of roots and shoots in pigeonpea (Okada et al., 1991). The greater sensitivity of pigeonpea to waterlogging (Hodgson et al., 1989; Troedson et al., 1990) could be one of the reasons for the 
larger reduction in dry matter accumulation in the ESD pigeonpea genotypes than in the SS legumes. Additionally, following a setback in growth as a result of saturated soil conditions, ESD pigeonpea genotypes were exposed to drought at the end of the growing season. Muchow (1985) has suggested that pigeonpea is particularly sensitive to late drought because of the time it takes to mature and its lack of capacity to adjust its time of maturity to the period of moisture availability. The short season legumes, apart from horse gram, matured earlier and therefore to some extent escaped late drought stress.

Delayed sowing reduced leaf area development in most of the crops. This appeared to have a positive effect on the partitioning of DM into grain yield in cowpea. The optimum LAI in cowpea is only 3-4, compared with 5-6 in pigeonpea (Rachie and Roberts, 1974; Lawn and Troedson, 1990). Delayed sowing improved the harvest index in cowpea; this almost compensated for the reduced dry matter accumulation and resulted in a significantly higher grain yield than in the other crops. The relation between grain yield and total dry matter was highly significant in the ESD pigeonpea genotypes $\left(r^{2}=0.95\right)$. There was no appreciable improvement in the harvest index of ESD genotypes with delayed sowing and the reduction in dry matter was therefore reflected in a proportionate reduction in yield. In pigeonpea genotypes, delayed sowing not only caused a decline in yield, but also affected seed quality as 100 -seed mass was significantly reduced. By contrast, in SS legumes yield variation with sowing time was mainly due to changes in the number of pods $\mathrm{m}^{-2}$; their harvest index tended to increase with delayed sowing.

On shallow Alfisols at Anantapur, the usual time of planting is July as June rainfall is less reliable. Overall growth and the yields attained by the crops in the normal sowings were comparable to those in the delayed sowings on mediumdeep Alfisols. In 1988, cowpea produced the maximum grain yield, suggesting that it is better adapted to shallow soil than the other crops. In 1989, however, its establishment was affected by root damage caused by an unidentified insect pest, which resulted in a poor grain yield. In all the crops, total dry matter and grain yield were reduced by delayed sowing. This was probably for reasons similar to those that caused reduced dry matter accumulation on the medium deep Alfisol. However, unlike the case on the medium deep Alfisol, yields of all the SS legumes were reduced significantly as a result of reduced DM production on the shallow Alfisol. Although harvest index improved with delayed sowing on the shallow soil, the increase was insufficient to offset the decline in dry matter.

The results of this study suggest that ESD pigeonpea genotypes have a yield advantage over SS legumes only if sown on time in medium-deep soils. They could therefore be recommended for rainfed cultivation in soils with a comparable pattern of moisture availability to that of the medium deep Alfisols in this experiment, as found in large areas of India and Africa, where ESD pigeonpea genotypes could potentially replace short-season legume crops in the normal cropping period. However, for contingency cropping on such soils the ESD pigeonpea genotypes may face competition from crops such as cowpea and black 
gram unless their adaptation to delayed sowing and shallow soils can be improved. Future work on improving the adaptation of ESD pigeonpea genotypes to rainfed conditions should therefore concentrate on increasing and stabilizing dry matter production, especially under conditions of soil moisture stress, whether caused by a deficit or excess.

Acknowledgements. The input of DrC. K. Ong, International Center for Research in Agroforestry (ICRAF), Nairobi, Kenya in the design and conduct of these studies is gratefully acknowledged. We thank technical staff of the Crop Physiology Unit, Legumes Program, ICRISAT, for competent and careful assistance in the conduct of these experiments. The senior author is grateful to Andhra Pradesh Agricultural University, and Dr D. L. Oswalt, Leader of the Human Resources Development Program, for providing research facilities.

\section{REFERENCES}

Chauhan, Y. S. (1990). Pigeonprea: optimum agronomic management. The Pigeonpea, 257-278 (Eds Y. L Nene, S. D. Hall and V. K. Sheila). Wallingford, Oxford, UK: (AB International.

Hodgson, A. S., Holland, J. F. \& Rayner, P. (1989). Effects of field slope and duration of furrow irrigation on growth and yield of six grain legumes on a waterlogging-prone Vertisol. Field Crops Research 22:165180).

Keig, (G. \& McAlpine, J. R. (1974). WATBAL.; A Computer System for the Estimation and Analysis of Soil Moisture Kegimes from Simple (limalic Dala. Technical Memorandum 74/4. Canberra, Australia: CSIRO.

laxman Singh, (iupta, S. C. \& Faris, D. (i. (1990)). Pigeonpra: breeding. The Pigeonpra, 375-399. (Eds Y

I. Nene, S. D. Hall and V. K. Sheila). Wallingtord, Oxford, UK: CAB International.

Lawn, R.J \& Troedson, R.J. (1990). Pigeconpea: physiology of yield formation. The Pigeonpea, 179-2018

(Edu Y. L. Nene, S. D. Hall and V. K. Slieila). Wallingford, Oxford, UK: CAB International.

Martin, J. H., Leonard, W. H. Stamp, D. L. (1976). Principles of Field Crop Production. New York. USA: Macmillan Publishing Co.

Muchow, R. C. (1985). Phenology, seed yield and water use of gr ain legumes grown under different soil water regimes in a semi-arid tropical environment. Field Crops Research 11:81-97.

Okada, K., Ac, N. Arihara, J. (1991). Soil acration status of Alfisols and Vertisols: a limiting factor for growth of pigeonpea. In Phosphonus Nutrition of Grain Legumes in the Semi-Arid Tropics, 139-155 (Eds C. Johansen, K. K. Lee and K. L. Sahrawat). Patancheru, India: ICRISAT

Rachie, K. O. Roberts, L. M. (1974). (irain legumes of the low-land tropics. Adrances in Agronomy 26:1132.

Singh, R. P. \& Subba Reddy, G. (1988) Identifying crops and cropping systems for water-limited environments. In Drought Research Priorities for the Dopland Tropics, 43-61 (Eds F. R. Bidinger and C. Johansen). Patancheru, India: ICRISAT.

Subramanian, V.B. (1983) Pulses and cilseeds in rainfed cropping systems. In Dyland Agricultural Research in India: Thrust in the Eighties, 25-41 (E.ds R. P. Singh and V. B. Subramanian). Hyderabad, India: AICRPDA.

Troedson, R. J., Wallis, E. S. \& Laxman Singh (1990) Pigeonpea: adaptation. The Pigeonpee, 159-177 (Eds Y. L. Nene, S. D. Hall and V. K. Sheila. Wallingford, Oxford, UK: CAB International.

Venkataratnam, N. V. Sheldrake, A. R. (1985). Second harvest yields of medium duration pigeonpea (Cajanus cajou) in peninsular India. Fiveld Crops Research 10:323-332. 